\title{
Basic and Nonbasic Employment Linkages
}

\author{
Stephen E. Miller and Mark S. Henry*
}

\section{Introduction}

The simple economic base multiplier is a widely used tool of regional economic analysis. Its popularity may be largely attributed to its low cost and ease of interpretation. However, recent theoretical and empirical work has cast doubt upon the use of simple economic base multipliers for short-run impact analysis. Romanoff $[12$, p. 124] has noted: “ . . the analytical capability of the economic base approach is actually well below the expectation of users, where in the traditional, open, one-equation economic base model interdependence is smaller than that obtained by the full, partially closed, two equation model which in turn, portrays only some of the interdependencies of the input-output model."

Several studies have failed to provide much empirical support for the existence of the economic base multiplier. From his review of the early regression analysis tests of the existence of economic base multipliers and their lag structures McNulty [9, p. 363] concluded that generally there was no agreement either theoretically or empirically on the time dimension of the basic-nonbasic employment relationship. In his own analysis, McNulty applied regression techniques to annual personal income estimates for SMSA's. After testing for the change in nonbasic income in response to a basic income change, he concluded $[9$, p. 367] that "the economic base theory of regional growth was found to fit the facts very well in the long run, but to provide a very poor explanation of short run regional economic development."

Polynomial distributed lag techniques have also been used to test for the time dimension of the basic-nonbasic relationship. In a study of Central Missouri Valley SMSA's, Lutrell and Gray [8] used first differences of quarterly employment data in an Almon model with zero restrictions for both endpoints, and a third degree polynomial with three lags. They reported that "with the exception of perhaps three SMSA's in the CMV, additional workers in local export occupations had only a slight impact on employment in the urban-oriented (nonbasic) sector of the local economy." Moriarty [10] used first differences of annual employment data for SMSA's stratified by size and geographical region. The data were used in a third degree polynomial model with three lags. Also, the most distant lag point was constrained to zero.

*Department of Agricultural Economics and Rural Sociology, Clemson University, Clemson, South Carolina. 
Moriarty's results tend to support the nonbasic to basic linkages. "The total nultipliers (summed over three periods) is significantly greater than inity...indicating that the growth of total employment is dependent upon the srowth of total manufacturing employment in large cities over time" $[10, p$. 202].

However, this conclusion by Moriarty may be invalid for two reasons. First, he selection of a third degree polynomial with a lag length of three years apsears to be arbitrary and, in fact, imposes, a priori, a lag structure on the data 14]. Second, use of annual differenced data precludes the detection of shorter lag responses.

Time series techniques which involve filtering the time series before ascertaining lead-lag relationships have only recently been applied to basic and nonbasic data. The filtering process serves to reduce the "spurious regression" problem encountered when working with autocorrelated time series [5]. Cook [2] applied a transfer function model to quarterly employment data from two counties in Washington. Cook [2, p. 89] found that basic employment changes "significantly affect changes in other employment in the current period, after one quarter, and after eight quarters." Giarratani-McNelis [3], and Spreen-Mulkey [13] employed time series techniques but generally found no statistically significant lags between basic and nonbasic time series. Giarratani and McNelis found, using annual income data for South Atlantic states, that there was little empirical evidence of basic income changes causing nonbasic income changes using a Granger test of causality [4]. However, quarterly and/or annual data may conceal shorter term responses (monthly, e.g.).

In the present study, we utilize time series techniques to test for the existence and structure of basic-nonbasic employment linkages. Our use of monthly data should allow detection of shorter lags than those observable in earlier studies which made use of quarterly and/or annual data.

\section{METHODOLOGY}

The methodology used here, univariate residual cross-correlation analysis, offers the advantage that the data are allowed to suggest the nature of the leadlag relationships. That is, a lag structure is not imposed a priori. This methodology is based on a concept due to Granger [4]; i.e., a time-ordered variable $\mathrm{X}$ is said to lead another time-ordered variable $\mathrm{Y}$ if $\mathrm{Y}$ may be better predicted with the use of the history of $X$ than without, with all relevant information (including Y's history) being used in either case. Haugh [6] and Haugh and Box [7] have adopted this criterion in assessing lead-lag relationships between time series. Since detailed discussions of the methodology are available elsewhere $[6,7,11]$, only a brief sketch will be given here.

Let $X_{t}$ and $T_{t}$ be the realizations at time $t$ of two stochastic processes. Associated with $X_{t}$ and $Y_{t}$ are white noise terms, $u_{t}$ and $v_{t}$, respectively. Also, $\mathrm{E}\left[\mathrm{u}_{\mathrm{t}}\right]=\mathrm{E}\left[\mathrm{v}_{\mathrm{t}}\right]=0 ; E\left[\mathrm{u}_{\mathrm{t}}^{2}\right]=\sigma_{\mathrm{u}}^{2} ; E\left[\mathrm{v}_{\mathrm{t}}^{2}\right]=\sigma_{\mathrm{v}}^{2}$. 
Following Haugh and Box [7] the theoretical cross-correlation between the u's and v's, defined at lag $\mathrm{k}$ as

$$
\rho \text { uv }(\mathrm{k})=\frac{\mathrm{E}\left[\mathrm{u}_{\mathrm{t}-\mathrm{k}}, \mathrm{v}_{\mathrm{t}}\right]}{\sigma_{\mathrm{u}} \sigma_{\mathrm{u}}}
$$

may be used to assess the lead-lag relationships between the original $\mathrm{X}$ and $\mathrm{Y}$ series. Some lead-lag relationships of interest as implied by patterns in the theoretical cross-correlation function are as follows [11, p. 15]:

Case $\quad \mathrm{I}: \rho$ uv $(\mathrm{k})=0$ for all $\mathrm{k} \rightarrow \mathrm{X}$ and $\mathrm{Y}$ are independent,

Case II: $\rho$ uv $(0)=0 \quad \rightarrow \mathrm{X}$ and $\mathrm{Y}$ are related instantaneously,

Case III: $\rho$ uv $(\mathrm{k})=0$ for some $\mathrm{k}>0 \rightarrow \mathrm{X}$ leads $\mathrm{Y}$,

Case IV: $\rho$ uv $(\mathrm{k})=0$ for some $\mathrm{k}<0 \rightarrow \mathrm{Y}$ leads $\mathrm{X}$,

Case $\quad \mathrm{V}: \rho$ uv $(\mathrm{k})=0$ for some $\mathrm{k}>0 \rightarrow$ Feedback between $\mathrm{X}$ and $\mathrm{Y}$. and for some $\mathrm{k}<0$.

Estimates of the u's and v's, denoted as the û's and v̂'s respectively, may be obtained via application of univariate time series modeling techniques [1]. Statistical tests of the significance of the calculated cross-correlations between the û's and $\hat{v}$ 's, denoted as the $r_{\hat{u} \hat{v}}(k)$ 's, may be used to infer the lead-lag relationships between $\mathrm{X}$ and $\mathrm{Y}$. The reason for examining the white noise series, rather than the original data, is that any autocorrelation in the original data would lead to overestimation of the significance of the cross-correlations [5, 11 ]. If $X$ and $Y$ are independent, the $r_{\hat{u} \hat{v}}(k)$ 's are asymptotically independently and normally distributed with zero mean and variance $n^{-1}$, where $n$ is the sample size [6].

As discussed by Pierce [11, p. 15], the hypothesis that $\mathrm{X}$ and $\mathrm{Y}$ are linearly independent (Case I holds) may be rejected at significance level $\alpha$ if

$$
\mathrm{QA}_{2 \mathrm{~m}+1}=\mathrm{n} \sum_{\mathrm{k}=-\mathrm{m}}^{\mathrm{m}}\left|\mathrm{r}_{\hat{\mathrm{u}} \mathrm{v}}(\mathrm{k})\right|^{2}>\mathrm{X}_{\alpha}{ }^{2}, 2 \mathrm{~m}+1
$$

where $\mathrm{X}_{\alpha}{ }^{2}, 2 \mathrm{~m}+1$ is the upper $\alpha$ percentage point of the chi-square distribution with d.f. $=2 \mathrm{~m}+1$; and $\mathrm{m}$ is chosen so as to include all $\rho_{\mathrm{uv}}(\mathrm{k})$ 's expected to differ from zero. The contention that X leads Y (Case III holds) is supported at significance level $\alpha$ if

$$
\mathrm{QB}_{\mathrm{m}}=\mathrm{n} \underset{\mathrm{k}=1}{\mathrm{~m}}\left|\mathrm{r}_{\hat{\mathrm{u}} \mathrm{v}}(\mathrm{k})\right|^{2}>\mathrm{X}_{\alpha}^{2}, \mathrm{~m}
$$

Similarly, Y leads X (Case IV) may be asserted at $\alpha$ if 


$$
\mathrm{QB}_{\overline{\mathrm{m}}}=\mathrm{n} \sum_{\mathrm{k}=-\mathrm{m}}^{-1}\left|\mathrm{r}_{\hat{\mathrm{u}} \hat{\mathrm{v}}}(\mathrm{k})\right|^{2}>\mathrm{X}_{\alpha}{ }^{2}, \mathrm{~m}
$$

If the inequalities in (3) and (4) hold simultaneously, then a feedback relationship between $\mathrm{X}$ and $\mathrm{Y}$ (Case $\mathrm{V}$ ) is indicated. Also, the significance of an individual $\mathrm{r}_{\hat{u} \hat{v}}(\mathrm{k})$ may be determined by comparison to its standard error, $(\mathrm{n}-\mathrm{k})^{-1 / 2}$

\section{DATA AND EMPIRICAL RESULTS}

The data for this analysis were comprised of the natural logs of monthly employment for the state of South Carolina and the Greenville-Spartanburg SMSA. Following the McNulty [9] approach, these employment series were assigned by two digit SIC groups to either basic (export) or nonbasic sectors based on the judgement of the researchers. For the Greenville-Spartanburg SMSA, manufacturing is export oriented with textiles, textile machinery and industrial chemicals dominating the manufacturing sector. Other components of the export base were assumed to be federal and state employment. All other nonagricultural sectors comprised the nonbasic sectors. Similar assumptions were made for the state data except that state employment was assumed to be part of the nonbasic sector.

The sampling intervals for the state and SMSA data were 1967-1978 and 1970-1979, respectively. Diffferences of order 1 and 12 were required to produce stationarity in all the series. These differencing operations resulted in sample intervals of length 131 for the state data and 107 for the SMSA data. Let $X_{t}, S_{t}, \bar{X}_{t}$, and $\bar{S}_{t}=$ the observation for month $t$ of the differenced state basic, state nonbasic, SMSA basic and SMSA nonbasic employment variables, respectively. Table 1 shows the estimated autocorrelation of these variables for 24 positive lags. If each series was random, the standard errors of individual autocorrelations could be approximated by $(n-k)^{-1 / 2}$ where $n$ is the sample length and $\mathrm{k}$ is the length of lag.

Note that all series in Table 1 have estimated autocorrelations exceeding their respective standard errors by a factor of 2 or more. The presence of autocorrelation may result in overestimation of the significance of cross-correlations between the $X_{t}$ 's and $S_{t}$ 's, and the $\bar{X}_{t}$ 's and $\bar{S}_{t}$ 's. The application of univariate residual cross-correlation is thus appropriate in this case.

The iterative model building process described by Box and Jenkins [1] resulted in the following univariate time series models.

\section{State}

Basic: $\hat{\mathrm{a}}_{\mathrm{t}}=\mathrm{X}_{\mathrm{t}}-.40 \mathrm{X}_{\mathrm{t}-1}-.24 \mathrm{X}_{\mathrm{t}-2}+.83 \hat{\mathrm{a}}_{\mathrm{t}-12} ; \mathrm{RSE}=.008$

Nonbasic: $\hat{b}_{\mathrm{t}}=\mathrm{S}_{\mathrm{t}}+.47 \hat{\mathrm{b}}_{\mathrm{t}-12} ; \mathrm{RSE}=.007$ 
TABLE 1

Estimated Autocorrelations for Differenced South Carolina and GreenvilleSpartanburg SMSA Employment Variables

\begin{tabular}{crrrr}
\hline & \multicolumn{5}{c}{ Variable } \\
\cline { 2 - 5 } Lag & $\mathrm{X}$ & $\mathrm{S}$ & $\overline{\mathrm{X}}$ & $\overline{\mathrm{S}}$ \\
\hline 1 & $.55^{*}$ & -.15 & .16 & .19 \\
2 & $.53^{*}$ & .02 & $.33^{*}$ & $.23^{*}$ \\
3 & $.29^{*}$ & .00 & .04 & .18 \\
4 & .17 & .07 & -.03 & .01 \\
5 & .05 & .14 & -.00 & .10 \\
6 & -.03 & -.03 & -.04 & .04 \\
7 & -.04 & -.09 & -.04 & .03 \\
8 & -.08 & -.01 & .03 & .05 \\
9 & -.15 & .13 & .01 & .07 \\
10 & $-.27^{*}$ & -.05 & -.15 & -.08 \\
11 & $-.26^{*}$ & .07 & -.06 & -.07 \\
12 & $-.54^{*}$ & $-.29^{*}$ & $-.55^{*}$ & $-.47^{*}$ \\
13 & $-.31^{*}$ & .06 & -.03 & -.06 \\
14 & $-.30^{*}$ & .07 & $-.24^{*}$ & -.12 \\
15 & -.14 & .02 & .01 & -.10 \\
16 & -.11 & -.04 & -.03 & .08 \\
17 & -.01 & .07 & .03 & .04 \\
18 & .02 & .03 & .01 & .01 \\
19 & .00 & -.03 & .03 & -.08 \\
20 & -.03 & -.01 & -.08 & -.08 \\
21 & -.04 & -.16 & -.03 & -.15 \\
22 & .01 & .05 & .06 & -.05 \\
23 & -.03 & .02 & -.05 & .03 \\
24 & .06 & -.12 & .12 & .10 \\
& & & & \\
\hline
\end{tabular}

Note: * indicates the estimated autocorrelation exceeds its estimated standard error by a factor of 2 or more.

\section{$S M S A$}

Basic: $\hat{\mathrm{c}}_{\mathrm{t}}=\overline{\mathrm{X}}_{\mathrm{t}}-.27 \overline{\mathrm{X}}_{\mathrm{t}-2}+.78 \hat{\mathrm{c}}_{\mathrm{t}-12} ; \mathrm{RSE}=.016$

Nonbasic: $\hat{\mathrm{d}}_{\mathrm{t}}=\overline{\mathrm{S}}_{\mathrm{t}}-.18 \overline{\mathrm{S}}_{\mathrm{t}-2}+.59 \hat{\mathrm{d}}_{\mathrm{t}-12} ; \mathrm{RSE}=.009$

where the â's, $\hat{b}$ 's, $\hat{c}$ 's, and $\hat{d}$ 's $=$ white noise residuals; and RSE = residual standard error. ' Calculated cross-correlations between the â's and $\hat{b}$ 's, and the $\hat{c}$ 's and d's for $-36 \leq \mathrm{k} \leq 36$ are reported in Tables 2 and 3, respectively. Qstatistics calculated from Tables 2 and 3 are reported in Table 4 . The contents of those tables motivate the following comments.

Looking first at the state results, the hypothesis that the basic and nonbasic series are independent may be rejected at the $10 \%$ level when $-6 \leq \mathrm{m} \leq 6$. Also, the contention that the basic series leads the nonbasic series is supported 
TABLE 2

Estimated Cross-Correlations Between White Noise Residuals of South Carolina Basic and Nonbasic Monthly Employment, 1967-78.

\begin{tabular}{|c|c|c|}
\hline \multirow{2}{*}{$\frac{\mathrm{Lag}}{1}$} & \multicolumn{2}{|c|}{ Positive lags of $\hat{a}_{t}(k>0)$ : Negative lags of $\hat{a}_{t}(k<0)$} \\
\hline & $.18^{*}$ & -.00 \\
\hline 2 & $.18^{*}$ & .05 \\
\hline 3 & .03 & -.12 \\
\hline 4 & .05 & .05 \\
\hline 5 & -.00 & -.10 \\
\hline 6 & $.23^{*}$ & -.02 \\
\hline 7 & .15 & .04 \\
\hline 8 & -.08 & -.09 \\
\hline 9 & .12 & -.02 \\
\hline 10 & -.01 & -.05 \\
\hline 11 & -.00 & .10 \\
\hline 12 & -.03 & .06 \\
\hline 13 & -.06 & -.08 \\
\hline 14 & .01 & .03 \\
\hline 15 & $-.20^{*}$ & .04 \\
\hline 16 & -.07 & .06 \\
\hline 17 & .08 & -.16 \\
\hline 18 & .13 & -.04 \\
\hline 19 & .06 & -.18 \\
\hline 20 & -.04 & -.07 \\
\hline 21 & -.01 & -.05 \\
\hline 22 & -.07 & .02 \\
\hline 23 & -.07 & .05 \\
\hline 24 & 18 & .17 \\
\hline 25 & -.05 & -.10 \\
\hline 26 & .01 & .06 \\
\hline 27 & -.10 & -.02 \\
\hline 28 & -.09 & -.18 \\
\hline 29 & -.07 & .14 \\
\hline 30 & .02 & -.19 \\
\hline 31 & .02 & .00 \\
\hline 32 & -.07 & -.08 \\
\hline 33 & -.04 & .06 \\
\hline 34 & -.03 & .11 \\
\hline 35 & .03 & -.14 \\
\hline 36 & -.02 & -.06 \\
\hline
\end{tabular}

Note: $\mathrm{rab}_{\mathrm{ab}}(0)=.04$

* At least two times greater than its standard error.

at the $5 \%$ level for $m=3,6,12$, and 24 . The hypothesis that the nonbasic series leads the basic series can be rejected at the $10 \%$ level for all values of $-\mathrm{m}$ considered. Large individual estimated cross-correlations occur at $\mathrm{k}=1$, 2,6 , and 15. No estimated cross-correlations exceed their respective standard 
TABLE 3

Estimated Cross-Correlations Between White Noise Residuals of GreenvilleSpartanburg SMSA Basic and Nonbasic Monthly Employment, 1970-79.

\begin{tabular}{|c|c|c|}
\hline \multirow{2}{*}{$\begin{array}{c}\text { Lag } \\
1\end{array}$} & \multicolumn{2}{|c|}{ Positive lags of $\hat{c}_{t}(k>0)$ :negative lags of $\hat{c}_{t}(k>0)$} \\
\hline & $.21^{*}$ & .07 \\
\hline 2 & .12 & .05 \\
\hline 3 & .17 & .03 \\
\hline 4 & .02 & -.10 \\
\hline 5 & .02 & .07 \\
\hline 6 & .12 & .12 \\
\hline 7 & -.04 & -.02 \\
\hline 8 & .12 & -.12 \\
\hline 9 & -.03 & .04 \\
\hline 10 & -.06 & -.06 \\
\hline 11 & -.01 & -.06 \\
\hline 12 & -.08 & -.09 \\
\hline 13 & -.09 & -.06 \\
\hline 14 & -.12 & -.07 \\
\hline 15 & -.08 & .02 \\
\hline 16 & .11 & .08 \\
\hline 17 & .12 & -.10 \\
\hline 18 & .11 & .09 \\
\hline 20 & -.19 & -.10 \\
\hline 21 & .04 & -.14 \\
\hline 22 & -.10 & -.13 \\
\hline 23 & -.05 & -.04 \\
\hline 24 & $-.22^{*}$ & .16 \\
\hline 25 & -.06 & .17 \\
\hline 26 & -.08 & -.00 \\
\hline 27 & -.08 & -.03 \\
\hline 28 & -.10 & .02 \\
\hline 29 & -.15 & .03 \\
\hline 30 & .05 & .08 \\
\hline 31 & -.05 & -.20 \\
\hline 32 & -.04 & -.16 \\
\hline 33 & .04 & .14 \\
\hline 34 & .06 & -.09 \\
\hline 35 & -.06 & .01 \\
\hline 36 & -.15 & .03 \\
\hline
\end{tabular}

Note: $\mathrm{r}_{\mathrm{c}} \hat{\mathrm{d}}(0)=.41$

* At least two times greater than its standard error.

errors when $\mathrm{k}<0$. These results indicate that the basic series leads the nonbasic, with no feedback from the nonbasic to the basic series being indicated.

Turning to the SMSA results, the hypothesis that the basic and nonbasic series are independent may be rejected at the $5 \%$ level when $\mathrm{m}=3,6,12,24$, and 36 . The contention that the basic series leads the nonbasic is supported at 
TABLE 4

Selected Q-Statistics for South Carolina and Greenville-Spartanburg SMSA.

\begin{tabular}{lcc}
\hline & \multicolumn{2}{c}{ Series } \\
\cline { 2 - 3 } Statistic & South Carolina & Greenville-Spartanburg SMSA \\
\hline $\mathrm{QA}_{7}$ & 11.03 & $28.23^{* *}$ \\
$\mathrm{QA}_{13}$ & $19.98^{*}$ & $32.99^{* *}$ \\
$\mathrm{QA}_{25}$ & 29.21 & $39.27^{* *}$ \\
$\mathrm{QA}_{49}$ & 59.43 & $70.73^{* *}$ \\
$\mathrm{QA}_{73}$ & 83.34 & $94.12^{* *}$ \\
$\mathrm{QB}_{3}$ & $8.61^{* *}$ & $9.35^{* *}$ \\
$\mathrm{QB}_{6}$ & $15.86^{* *}$ & $10.98^{*}$ \\
$\mathrm{QB}_{12}$ & $21.67^{* *}$ & 13.87 \\
$\mathrm{QB}_{24}$ & $37.31^{* *}$ & 32.32 \\
$\mathrm{QB}_{36}$ & 41.91 & 41.61 \\
$\mathrm{QB}_{\overline{3}}$ & 2.21 & 0.89 \\
$\mathrm{QB}_{\overline{6}}$ & 3.90 & 4.02 \\
$\mathrm{QB}_{\overline{12}}$ & 7.34 & 7.42 \\
$\mathrm{QB}_{\overline{24}}$ & 21.92 & 20.42 \\
$\mathrm{QB}_{\overline{36}}$ & 41.23 & 34.52 \\
\hline
\end{tabular}

${ }^{*}\left({ }^{* *}\right)$ Denotes significance at the $10(5)$ percent level.

the $5 \%$ level when $\mathrm{m}=3$, and at the $10 \%$ level when $\mathrm{m}=6$. There is no evidence of feedback from the nonbasic to the basic series since all of the calculated QB-statistics for $\mathrm{k}<0$ fail to exceed their respective critical values. The largest individual estimated cross-correlation occurs at $\mathrm{k}=0$, with other large estimated cross-correlations occurring at $\mathrm{k}=1$ and 24 . When $\mathrm{k}<0$, none of the estimated cross-correlations exceed their respective standard errors by a factor of two or more.

\section{SUMMARY AND CONCLUSIONS}

Time series techniques are used here to test for the linkage between basic and nonbasic employment changes at the state and SMSA levels in South Carolina. The estimated autocorrelations of these monthly basic and nonbasic employment series indicate likely overestimation of the significance of crosscorrelations between the raw employment data. Use of the univariate residual cross-correlation technique is appropriate in this case.

The empirical results lead to rejection of the hypothesis of short-run independence of the basic and nonbasic series for both the SMSA and state levels, with more convincing results at the SMSA level. There is also evidence that the basic series lead the nonbasic series and that there is an apparent absence of feedback from the nonbasic to basic series. In contrast to McNulty's findings [9], these results provide support for the notion of a short-run basic to 
nonbasic linkage. While McNulty finds that no significant relationship between basic and nonbasic income change occurs in his analysis for periods of less than four years, we find evidence that there is a statistically significant relationship between short-run basic and nonbasic employment change. Our findings are similar in this respect to those of Cook [2]. Accordingly, although the exact nature of the lag relationship between basic and nonbasic employment is likely to vary from case to case, we conclude that short-run employment multipliers do exist and can be useful tools for economic impact analysis.

\section{FOOTNOTES}

1. The residuals were deemed to be white noise based on the absence of any patterns in their estimated autocorrelation and partial autocorrelation functions, and the "portmanteau" test suggested by Box and Jenkins [ 1, pp. 291-92].

Values of the test statistic for the first twentyfour autocorrelations of the residuals from Equations (3)-(6) were 15.67, 12.99, 13.07, and 18.57 , respectively.

\section{REFERENCES}

1. Box, G. E. P., and G. M. Jenkins. Time Series Analysis: Forecasting and Control. Rev. Ed. San Francisco: Holden-Day, 1976.

2. Cook, Thomas. "An Application of the Transfer Function to an Economic-Base Model." Annals of Regional Science 13 (1979): 81-92.

3. Giarratani, F. and P. D. McNelis. "Time Series Evidence Bearing on Crude Theories of Regional Growth." Land Economics (May, 1980) Forthcoming.

4. Granger, C. W. J. "Investigating Casual Relations by Econometric Models and Cross Spectral Methods." Econometrica 37 (1969): 424-38.

5. Granger, C. W. J., and P. Newbold. "Spurious Regressions in Econometrics." Journal of Econometrics 2 (1974): 111-20.

6. Haugh, L. D. "Checking the Independence of Two Covariance-Stationary Time Series: a Univariate Residual Cross-Correlation Approach." Journal of the American Statistical Association 71 (1976): 378-85.

7. Haugh, L. D., and G. E. P. Box. "Identification of Dynamic Regression (Distributed Lag) Models Connecting Two Time Series." Journal of the American Statistical Association 71 (1977): 121-30.

8. Lutrell, C. B., and C. M. Gray. "Metropolitan Area Growth: A Test of Export Base Con- cept." Review Federal Reserve Bank of St. Louis Reprint Series Number 58.

9. McNulty, J. "A Test of the Time Dimension in Economic Base Analysis." Land Economics 53 (1977): 359-368.

10. Moriarty, B. "The Distributed Lag Between Metropolitan Area Employment and Population Growth." Journal of Regional Science 16:2 (1976): 195-212.

11. Pierce, D. A. "Relationships-and the Lack Thereof-Between Economic Time Series, with Special Reference to Money and Interest Rates." Journal of the American Statistical Association 71 (1977): 11-22.

12. Romanoff, E. "The Economic Base Model: A Very Special Case of Input-Output Analysis." Journal of Regional Science 14:1 (1974): 121-129.

13. Spreen, T. and W. D. Mulkey. "The Lagged Effect of Basic Employment Change in a Regional Economy." (Unpublished paper presented at the Southern Regional Science Association meetings, Savannah, Georgia, April 13-15, 1980.)

14. Spreen, T., and W. D. Mulkey. "The Lagged Effect of Basic Employment Changes in the Florida Economy, 1955-1974." (Unpublished paper presented at the Southern Regional Science Association meetings, Nashville, Tennessee, April 5-6, 1979.) 